\title{
Symmetric volatility forecast models for crude oil price in Nigeria
}

\author{
Onyeka-Ubaka J.N. ${ }^{*}$, Agwuegbo S.O.N. ${ }^{2}$, Abass O. ${ }^{3}$, Imam R.O. ${ }^{1}$ \\ ${ }^{1}$ Department of Mathematics, Faculty of Science, University of Lagos, Nigeria \\ ${ }^{2}$ Department of Statistics, School of Science, Federal University of Agriculture, Abeokuta, Nigeria \\ ${ }^{3}$ Department of Computer Sciences, Bells University, Ota, Nigeria
}

Corresponding Author Email: jonyeka-ubaka@unilag.edu.ng

https://doi.org/10.18280/mmc_d.390102

Received: 21 January 2018

Accepted: 15 April 2018

\section{Keywords:}

symmetric, forecast, ARIMA models, volatility clustering

\begin{abstract}
Oil price data are available at a high frequency and therefore, there is increasing evidence of the presence of statistically significant correlations between observations that are large apart and possibility of conditional heteroskedasticity. This paper empirically analyzes the crude oil price return volatility patterns using autoregressive integrated moving average (ARIMA) and generalized autoregressive conditional heteroskedasticity (GARCH) family models. The results reveal that $\operatorname{GARCH}(1,1)$ and ARIMA $(1,1,0)$ models perform well in capturing the stylistic features present in high frequency crude oil prices in Nigeria within the sampled period. The Holt-Winters forecast made for twenty six (26) months using ARIMA $(1,1,0)$ was approximately close to the real price of crude oil per barrel as evident from the $95 \%$ confidence interval estimates. The paper practically disseminates independent and impartial crude oil price information to promote sound policymaking, efficient markets and understanding of crude oil price and its interaction with the economy and the environment.
\end{abstract}

\section{INTRODUCTION}

There is always a lot of interest in the energy markets. Oil, natural gas, coal, electricity and other energy commodities attract attention from producers, consumers, investors and traders. These commodities and their prices affect every inhabitant of planet earth. Prices of all of these energy commodities can be very volatile. While we are all consumers of energy, the energy commodities are an important input for most businesses - in many cases they are key cost of goods sold components. Therefore, energy prices in mono-economy like Nigeria have a huge influence on the price of many other commodities and finished goods. This higher crude oil prices directly affect the cost of gasoline, home heating oil, manufacturing and electric power generation. According to the United States energy information administration (EIA), 96\% of transportation relies on oil, $43 \%$ of industrial product, $21 \%$ of residential and commercial, and only $3 \%$ of electric power. However, if oil prices rise, then so does the price of natural gas, which is used to fuel $14 \%$ of electric power generation, $73 \%$ of residential and commercial, and $39 \%$ of industrial production, EIA [9]. High oil prices translate to high gas prices. Petroleum is also an ingredient in fertilizer. This, combined with higher transportation costs, increases food prices. High oil prices will ultimately increase inflation while low oil prices will lead to deflation which may cause recession in the long run.

Fluctuations in global crude oil prices have always been the focus of the economic and financial news. The higher crude oil prices rise, the more positive is the economic outlook for petroleum exporters. In contrast, countries dependent on petroleum imports suffer to varying degrees from those same higher prices as import bills increase. The activities of the restive Niger-Delta Youths and some illegal oil refineries in the South-South zone of Nigeria that has caused a lot of harm in terms of oil production and export in Nigeria - thereby affecting tanker shipping to the record loss of up to 200,000 barrels of crude oil a day, Imam [11]. The loss has prompted the late President Umaru Musa Yar'adua led government to give amnesty programme in 2009 to calm hostilities in the oil rich Niger Delta region. Estimates for the price per barrel for crude oil from leading financial and multilateral institutions are thus closely monitored by governments, investors and consumers alike. In this paper, we consider an autoregressive integrated moving average (ARIMA) and generalized autoregressive conditional heteroskedaticity (GARCH) models which statistically predict future points with respect to time-varying phenomena. There are three components to an ARIMA model, as a combination of autoregressive (AR), integrated (I), and moving-average (MA) models. Autoregressive revolves around regressing the variable of interest (in this case, the price of oil) on its prior terms. The "I" part of the model is generally applied when the data in the sample are non-stationary (i.e., the joint probability distribution of the variables under consideration change over time). The moving-average model states that the output variable linearly depends on the present and past values of a stochastic term.

\section{LITERATURE REVIEW}

Empirical studies show that models which present some nonlinearity can be modelled by conditional specifications, in both conditional mean and variance, Onyeka-Ubaka et al. [18]. A stochastic process $\left\{y_{t}\right\}_{t=-\infty}^{\infty}$ is a model that describes the 
probability structure of a sequence of observations over time Zhu [21]. A time series $y_{t}$ is a sample realization of a stochastic process that is observed only for a finite number of periods, indexed by $t=1,2, \cdots, T$, Onyeka-Ubaka [15]. A time series $y_{t}$ which is integrated of order $d$ has the ARIMA if it is represented in the form:

$\Phi(L)(1-L)^{d} y_{t}=\mu+\Theta(L) \varepsilon_{t}$

where $(1-L)$ is the integrated of order $d, \varepsilon_{t}$ is independently and normally distributed with zero mean and constant variance, and $\mathrm{L}$ denotes the lag operator. In ARIMA parlance, time series is a linear function of past actual values and random shocks.

The Autoregressive conditional heteroskedasticity $(\mathrm{ARCH})$ process introduced by Engle [8] and Bollerslev [3] explicitly recognized the difference between the unconditional and the conditional variance allowing the latter to change over time as a function of past errors. Let $\varepsilon_{t}$ denote a real-valued discretetime stochastic process and $\Psi_{t}$ the information set $(\sigma-$ field $)$ of all information through time $t$. then

$$
\begin{aligned}
& \varepsilon_{t} \mid \Psi_{t-1} \sim N\left(0, \sigma_{t}^{2}\right) \\
& \sigma_{t}^{2}=\alpha_{0}+\sum_{i=1}^{q} \alpha_{i} \varepsilon_{t-i}^{2}+\sum_{j=1}^{p} \beta_{j} \sigma_{t-j}^{2}=\alpha_{0}+\mathrm{A}(L) \varepsilon_{t}^{2}+\mathrm{B}(L) \sigma_{t}^{2}
\end{aligned}
$$

where

$p \geq 0, q \geq 0, \alpha_{0}>0, \alpha_{i} \geq 0 \quad i=1,2, \cdots, q$ and $\beta_{j} \geq 0 j=1,2, \cdots, p$.

These conditions on parameters ensure strong positivity of the conditional variance, Onyeka-Ubaka and Abass [16]. For $p=$ 0 the process reduces to the $\operatorname{ARCH}(q)$ process and for $\mathrm{p}=\mathrm{q}=$ 0 is simply white noise. If an autoregressive moving average model (ARMA model) is assumed for the error variance, the model is a generalized autoregressive conditional heteroskedasticity (GARCH) model, Bollerslev [3]. In that case, the GARCH (p, q) model (where $p$ is the order of the GARCH terms $\sigma^{2}$ and $q$ is the order of the ARCH terms $e^{2}$ ) is given by

$\sigma_{t}^{2}=\alpha_{1} e_{t-1}^{2}+\cdots+\alpha_{q} e_{t-q}^{2}+\beta_{1} \sigma_{t-1}^{2}+\cdots+\beta_{p} \sigma_{t-p}^{2}=\alpha_{0}+$ $\sum_{i=1}^{q} \alpha_{i} e_{t-i}^{2}+\sum_{j-1}^{p} \beta_{j} \sigma_{t-j}^{2}$

\section{METHODOLOGY}

Generally, when testing for heteroskedasticity in statistical or econometric models, the best test is the white noise test. However, when dealing with time series data, this means to test for ARCH errors and GARCH errors, the lag length $p$ of a $\mathrm{GARCH}(\mathrm{p}, \mathrm{q})$ process is established in three steps:

(i) Estimate the best fitting AR (q) model

$$
\begin{aligned}
& y_{t}=a_{0}+a_{1} y_{t-1}+\cdots+a_{q} y_{t-q}+e_{t}=a_{0}+\sum_{i=1}^{q} a_{i} y_{t-i}+ \\
& e_{t}
\end{aligned}
$$

(ii) Compute and plot the autocorrelations of

$$
\rho=\frac{\sum_{t=i+1}^{T}\left(\hat{e}_{t}^{2}-\hat{\sigma}_{t}^{2}\right)\left(\hat{e}_{t-1}^{2}-\hat{\sigma}_{t-1}^{2}\right)}{\sum_{t=1}^{T}\left(\hat{e}_{t}^{2}-\hat{\sigma}_{t}^{2}\right)^{2}}
$$

(iii) To estimate the total number of lags, use the Ljung-Box test until the value of these are less than, say, $5 \%$ significant. The Ljung-Box Q-statistic follows $\chi^{2}$ distribution with $n$ degrees of freedom if the squared residuals $e_{t}^{2}$ are uncorrelated. It is recommended to consider up to $\frac{T}{4}$ values of $n$. The null hypothesis states that there are no ARCH or GARCH errors. Rejecting the null thus means that such errors exist in the conditional variance [13].

The most commonly used stationarity test, the KPSS test, is due to Kwiatkowski, Phillips, Schmidt and Shin. The integration properties of a $y_{t}$ may also be investigated by testing the null hypothesis that the series is stationary against a unit root. Kwiathowski et al. [12] derived a test for this pair of hypothesis. Assuming no linear trend term, the data generating process is given as

$y_{t}=x_{t}+z_{t}$

where $x_{t}$ a random is walk, $x_{t}=x_{t-1}+\varepsilon_{t}, \quad \varepsilon_{t} \sim \operatorname{iid}\left(0, \sigma_{\varepsilon}^{2}\right)$ and $z_{t}$ is a stationary process. KPSS process denotes the following test statistics:

$\mathrm{T}^{-2} \sum_{t=1}^{n} \frac{S_{t}^{2}}{\hat{\sigma}_{\infty}^{2}}$

where $S_{t}=\sum_{j=1}^{n} \hat{x}_{j}$ with $w_{j}=y_{j}-\bar{y}$ and $\hat{\sigma}_{X}^{2}$ an estimator of the long run variance of $z_{t}, \sigma_{\infty}^{2}=\lim T^{-1} \operatorname{var}\left(\sum_{t=1}^{T} z_{t}\right)$. The null hypothesis of the test is $H_{0}: \sigma_{\varepsilon}^{2}=0$ against alternative hypothesis $H_{1}: \sigma_{\varepsilon}^{2} \neq 0$. This test uses the Bartlett window with a lag truncation parameter

$\mathrm{I}_{q}=q\left[\frac{\mathrm{T}}{100}\right]^{\frac{1}{4}}$

where $\quad \sigma_{\varepsilon}^{2}=T^{-1} \sum_{t=1}^{T} \widehat{w}^{2}+2 \sum_{j=1}^{T} w_{j}\left[T^{1} \sum_{t=j+1}^{T} \widehat{w}_{t} \widehat{w}_{t-j}\right]$ and $w_{j}=1-\frac{j}{I_{4}+I}$, Bartlett [2].

Reject the null hypothesis if the test statistics is greater than the asymptotic critical values.

To select the best ARIMA (p, d, q) type of models fitted for the company, their goodness of fit have been compared using following criteria:

Akaike Information Criterion (AIC): The AIC takes into account both how well the model fits the observed series and the number of parameters to be used in the fit. AIC due to Akaike [1] is defined as

$$
\mathrm{A} I C=\mathrm{N}\left(\hat{\delta}^{2}+1\right)+2(p+1)
$$

where $\mathrm{N}$ is the number of dataset, $\hat{\delta}$ is the parameter and $2(\mathrm{p}+$ $1)$ is the penalty for including excess parameters. The minimum AIC criterion produced a selected model which is hopefully closer to the best possible choice.

Schwartz [20] developed the Schwartz information criterion (SIC) for taking decisions about the regress subset. Later Engle et al. [8] use this criterion as a tool for determining the order of auto regression and they defined this criterion as: 


$$
S I C=\hat{\delta}\left(-\frac{p}{\mathrm{~N}}\right)^{\frac{1}{2}} \mathrm{~N}^{\frac{p}{2 \mathrm{~N}}}
$$

where, the parameters bear the usual meaning. Schwartz also shows that this criterion is better than AIC. The model with minimum SIC assumes to describe the data series adequately and the minimum value of this criterion is desirable for the adequacy of a model.

\section{RESULTS AND DISCUSSION}

\subsection{Empirical analysis of crude oil price data (January 2003 - October 2016)}

The identification starts with time series plot which may reveal one of the following characteristics: (i) trends either in the mean level or variance of the time series (ii) extreme values and outliers (iii) seasonality. The time plot of the series (Figure 1) exhibit a non-stationary upward trend pattern, suggesting perhaps that the mean and the variance of the log of crude oil price has been changing with time or over time in Nigeria. The trend captures investors' behaviour as they stamped out of the falling real estate and stock markets, and divert their funds to oil futures. This sudden surge drove up oil prices. The correlogram autocorrelation function (ACF) and partial autocorrelation function (PACF) of the crude oil price's log of the data series before differencing at various lags are very high, (at lag $1=0.9777$ ) up to a lag of 24 months (at lag $24=0.2167$ ); these are individually statistically significantly different from zero, out of the $95 \%$ confidence bounds. The autocorrelation starts at a very high value and a decline (spikes down) very slowly toward zero as the lags lengthens, showing a purely moving average (MA) series. The gradual decay in the ACF simply suggests that each successive lag affects the present and future observations less as time goes on. Therefore, events in the oil market from April 2015 are less likely to affect the market than those from September 2016. This seems self evident, but each dataset is different. We conclude from the result of the ACF that there is need for differencing which indicate the series is an ARIMA process.

Since the time series is not stationary, we have to make it stationary before we can apply the Box-Jenkins [4] methodology. This can be done by differencing the series once $(d=1)$ and plot as seen Figure 2. A visual inspection of the plot show the series has constant mean and approximately constant variance. This phenomenon of volatility clustering first observed by Mandelbrot [14], that is, periods (in which the oil price) shows wide swings for an extended time period followed by periods in which there is relative calm. The plots of the ACFs decrease fast until they are not statistically different from zero. This suggests that the data series is now stationary, hence a formal application of the Augmented Dickey-Fuller (ADF) [7] and Kwiatkowski Phillips Schmidst and Shin (KPSS). The results of the test are given in Table 1 which shows the entire test statistics of the ADFs are less than the critical region; we reject the null hypothesis and therefore conclude that there is no unit root or the time series is stationary. Likewise the KPSS tests, the test statistics are all less than the p-values; we therefore accept the null hypothesis and conclude that the data series is stationary around a deterministic trend.

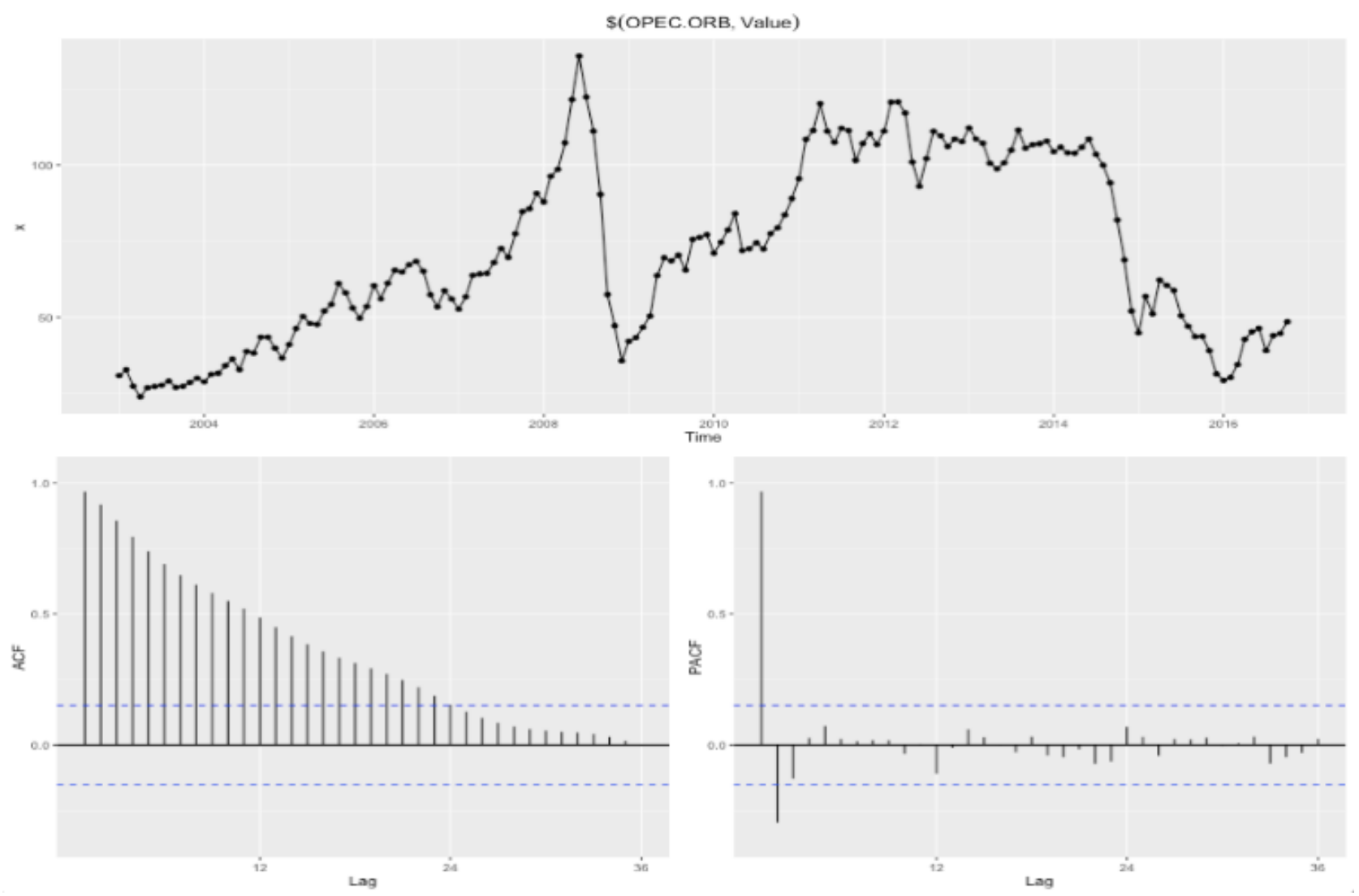

Figure 1. Time plot, ACF and PACF of original series 


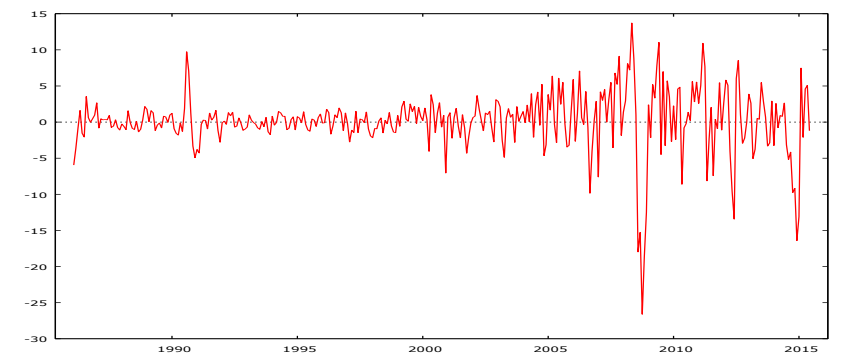

Figure 2. The plot of $1^{\text {st }}$ difference crude oil price data
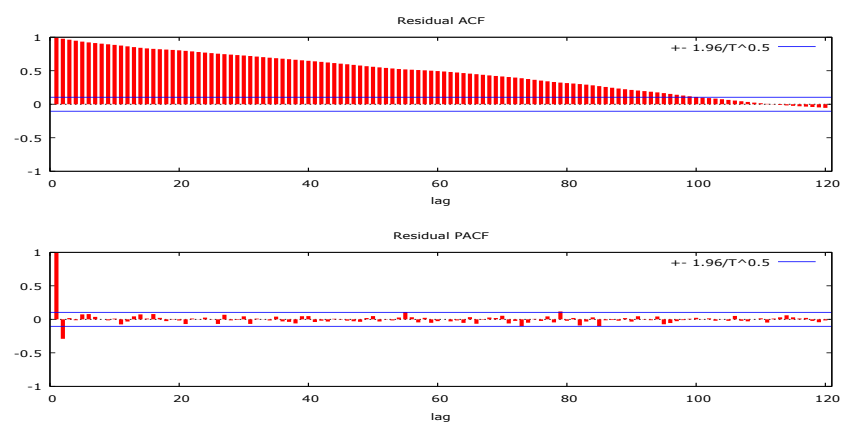

Figure 3. Plots of the ACF and PACF of $1^{\text {st }}$ difference crude oil price data
Table 1. Unit root tests after differencing (ADF and KPSS Tests)

\begin{tabular}{|c|c|cc|}
\hline Test & Test Statistics & Critical/P-value \\
\hline ADF without Constant & -1.0963 & 0.3271 \\
ADF with Constant & -2.1837 & 0.3365 \\
ADF with Constant and & -2.2059 & 0.5124 \\
Trend & & & $5 \%$ \\
& & $1 \%$ & 0.579 \\
KPSS without Trend & 0.1168 & 0.841 & 0.247 \\
KPSS with Trend & 0.1275 & 0.339 & 0. \\
\hline
\end{tabular}

At the estimation stage, estimates are usually calculated. The estimation was done using R-console. The model comparison and selection presented in Table 2 tested eight (8) models with low AIC, Hannan-Quinn Information Criterion (HQC) and SIC which is common in ARIMA modelling and find the best models among them. ARIMA $(1,1,0)$ model is selected because they have minimum AIC, HQC and SIC. The estimates of the parameters of the model, shown in Table 3, indicates that AR (1), AR (2) and MA (1) models are significant at the 0.05 significance level. The ACF and PACF of ARIMA $(1,1,0)$ model of the residuals also show that the residuals are white noise series.

Table 2. Model comparison and selection

\begin{tabular}{|c|c|c|c|c|}
\hline Model & AIC & HQC & SBC & RSquare \\
\hline ARIMA $(0,1,1)$ & -407.2910 & -403.4891 & -349.7182 & 0.892 \\
\hline ARIMA $(0,1,2)$ & -412.2325 & -407.7312 & -354.5231 & 0.880 \\
\hline ARIMA $(1,1,0)$ & -412.9376 & -409.9117 & -389.4782 & 0.975 \\
\hline ARIMA $(1,1,1)$ & -410.3042 & -406.8533 & -387.4449 & 0.943 \\
\hline ARIMA $(1,1,2)$ & -408.2910 & -401.7855 & -386.7182 & 0.832 \\
\hline ARIMA $(2,1,0)$ & -412.1525 & -406.3079 & -388.5231 & 0.810 \\
\hline ARIMA (2, 1, 1) & -407.3376 & -402.1347 & -367.4785 & 0.905 \\
\hline ARIMA (2, 1, 2) & -405.3042 & -398.6475 & -346.3469 & 0.924 \\
\hline
\end{tabular}

Table 3. Parameter estimates

\begin{tabular}{|c|c|c|c|c|c|}
\hline Term & Lag & Estimate & Std Error & t ratio & Prob $>|\mathbf{t}|$ \\
\hline AR (1) & 1 & 1.3610442 & 0.1441658 & 12.35 & 0.0166 \\
Intercept & 0 & 510.915058 & 284.02189 & 1.80 & 0.0798 \\
\hline AR (2) & 2 & -0.3204135 & 0.1493262 & -2.25 & 0.0169 \\
Intercept & 0 & 629.831074 & 294.101347 & 1.67 & 0.0856 \\
\hline MA (1) & 2 & -1.1792053 & 0.1453790 & -1.87 & 0.0187 \\
Intercept & 0 & 533.279061 & 289.135742 & 0.99 & 0.6521 \\
\hline
\end{tabular}

The confidence intervals at which forecasts are made rely on the assumption that the residuals (i.e., the difference between the values measured as part of the regression and the theoretical or true values) are normally distributed and uncorrelated as evident from Figure $4 \mathrm{a}$. We see from the Figure $4 \mathrm{~b}$ that there exists a prolonged low volatility from 2003 to 2007 and then there is a sudden shock, spike which is immediately followed by a prolonged low volatility. In other words, periods of high volatility are followed by periods of high volatility and periods of low volatility is followed by periods of low volatility. When the residual behaves like this, it suggests that the error term or residual is conditionally heteroskedastic and it can be represented by $\mathrm{ARCH}$ and GARCH models.
The GARCH model is usually much more parsimonious and often a GARCH $(1,1)$ model is sufficient, this is because the GARCH model incorporates much of the information that a much larger ARCH model with large number of lags would contain, Onyeka-Ubaka, et al. [17]. If a negative return shock causes more volatility than a positive return shock of the same size, the GARCH model under predicts the amount of volatility following bad news and over predicts the amount of volatility following good news. The parameter estimates and model checking are presented in Tables 4 and 5. The forecast of $\operatorname{GARCH}(1,1)$ model is achieved in its estimation. 

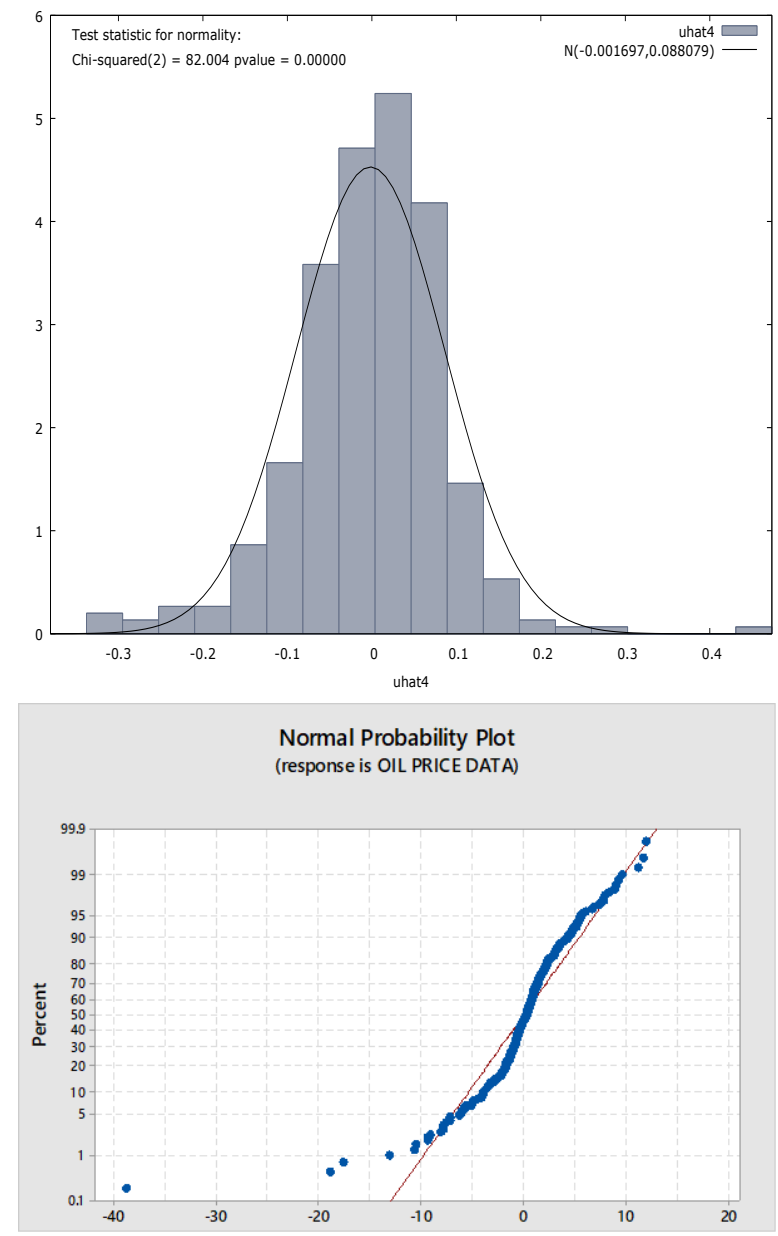

Figure 4. The (a) histogram (b) Normal Probability Plot is approximately normal

Table 4. Parameter estimation for $\operatorname{GARCH}(1,1)$

\begin{tabular}{|c|c|c|c|c|}
\hline Parameter & Coefficient & Std Error & t-ratio & P-value \\
\hline $\boldsymbol{\alpha}_{\mathbf{0}}$ & 0.758941 & 0.352719 & 2.167 & 0.0321 \\
\hline $\boldsymbol{\alpha}_{\mathbf{1}}$ & 0.171065 & 0.201973 & 2.684 & 0.0250 \\
\hline $\boldsymbol{\beta}_{\mathbf{1}}$ & 0.827503 & 0.078295 & 7.539 & $4.63 \mathrm{e}-012$ \\
\hline
\end{tabular}

Table 5. Summary of the result of GARCH $(1,1)$ model checking

\begin{tabular}{|c|c|c|}
\hline Test & Test Statistics & P-value \\
\hline Box-Pierce Q-Statistic & 59.26313 & 0.138 \\
\hline ARCH-LM & 89.7551 & 0.234167 \\
\hline
\end{tabular}

\subsection{Forecast evaluation with ARIMA models}

Let assume that $y_{1}, y_{2}, \cdots, y_{T}$ follows the general ARIMA ( $\mathrm{p}, \mathrm{d}, \mathrm{q})$ model that can be written in terms of a linear combination of past values and past errors, $\varepsilon_{t}$ :

$y_{t}=\frac{\Theta(L)}{\Phi(L) \Delta^{d}} \varepsilon_{t}=\psi_{\infty}(L) \varepsilon_{t}=\left(1+\psi_{1} L+\psi_{2} L^{2}+\cdots\right) \varepsilon_{t}$

If no differencing is done $(d=0)$, the models are usually referred to as ARMA (p, q) models. The future value $y_{T+\ell}$ is generated by model (11). Thus

$y_{T+\ell}=\varepsilon_{T+\ell}+\psi_{1} \varepsilon_{T+\ell-1}+\psi_{2} \varepsilon_{T+\ell-2}+\cdots$ where $y_{T}(\ell)$, the $\ell$-step ahead forecast of $y_{T+\ell}$ made at origin $\mathrm{T}$. The optimal forecast of $y_{T+L}$ is the conditional expectation of $y_{T+L}$ given the information set, denoted by $E\left[y_{T+\ell} \mid Y_{T}\right]$. The term optimal is used in the sense that minimizes the Mean Squared Error (MSE), Contreras et al. [6]. If the process is normal, the Minimum MSE forecast (MMSE) is linear. Therefore, the optimal forecast $\ell$-step ahead is

$$
\begin{gathered}
y_{T}(\ell)=E\left[y_{T+\ell} \mid Y_{T}\right] \\
=E\left[\varepsilon_{T+\ell}+\psi \varepsilon_{T+\ell-1}+\psi_{2} \varepsilon_{T+\ell-2}+\cdots \mid Y_{T}\right] \\
=\psi_{\ell} \varepsilon_{T}+\psi_{\ell+1} \varepsilon_{T-1}+\psi_{\ell+2} \varepsilon_{T-2}+\cdots
\end{gathered}
$$

Since past values $\varepsilon_{T+j}$, for $j \leq 0$, are known and future value of $\varepsilon_{T(j)}$, for $\mathrm{j}>0$ have zero expectation. The $\ell$-step ahead forecast error is a linear combination of the future shocks entering the system after time $\mathrm{T}$ :

$e_{T}(\ell)=y_{T+\ell}-y_{T}(\ell)=\varepsilon_{T+\ell}+\psi_{1} \varepsilon_{T+\ell-1}+\cdots+\psi_{\ell-1} \varepsilon_{T+1}$

Since $E\left[\varepsilon_{T}(\ell) \mid \Upsilon_{T}\right]=0$, the forecast $y_{T}(\ell)$ is unbiased with MSE given as

$\operatorname{MSE}\left[y_{T}(\ell)\right]=\operatorname{Var}\left(e_{T}(\ell)\right)=\sigma_{\varepsilon}^{2}\left(1+\psi_{1}^{2}+\cdots+\psi_{\ell}^{2}\right)$

Given these results, if the process is normal, the $(1-\alpha)$ forecast interval is

$\left[y_{\mathrm{T}}(\ell) \pm Z_{\frac{\alpha}{2}} \sqrt{\operatorname{Var}\left(e_{\mathrm{T}}(\ell)\right)}\right]$

For $\ell=1$, the one $=$ step ahead forecast error is $e_{T}(\ell)=$ $y_{T+1}-y_{T}(1)=\varepsilon_{T+1}$, therefore $\sigma_{\varepsilon}^{2}$ can be interpreted as the one-step ahead prediction error variance.

In computing forecasts, ARIMA ( $p, d, q)$ model can be written as

$\pi_{p+d}(L) y_{t}=\left(1-\pi_{1} L-\pi_{2} L^{2}-\cdots-\pi_{p+d}\left(L^{p+d}\right)=\Theta(L) \varepsilon_{t}\right.$

where $\pi_{p+d}(L)=\Phi_{p}(L)(1-L)^{d}$. Thus the future value of $y_{T+\ell}$ generated by (12) is

$$
\begin{aligned}
y_{T+\ell}=\pi_{1} y_{T+\ell-1} & +\cdots+\pi_{p+d} y_{T+\ell-p-d}+\varepsilon_{T+\ell}+\theta_{1} \varepsilon_{T+\ell-1} \\
& +\cdots+\theta_{q} \varepsilon_{T+\ell-q}
\end{aligned}
$$

and the MMSE forecast is given by the expectation conditional to the information set:

$$
\begin{aligned}
y_{\mathrm{T}}(\ell)= & \mathrm{E}\left[y_{\mathrm{T}+\ell} \mid \mathrm{Y}_{\mathrm{T}}\right]=\pi_{1} \mathrm{E}\left[y_{\mathrm{T}+\ell-1} \mid \mathrm{Y}_{\mathrm{T}}\right]+\cdots+\pi_{p+d} \mathrm{E}\left[y_{\mathrm{T}+\ell-p-d} \mid \mathrm{Y}_{\mathrm{T}}\right]+\mathrm{E}\left[\varepsilon_{\mathrm{T}+\ell} \mid \mathrm{Y}_{\mathrm{T}}\right]+ \\
& \theta_{1} \mathrm{E}\left[\varepsilon_{\mathrm{T}+\ell-1} \mid \mathrm{Y}_{\mathrm{T}}\right]+\cdots+\theta_{q} \mathrm{E}\left[\varepsilon_{\mathrm{T}+\ell-q} \mid \mathrm{Y}_{\mathrm{T}}\right]
\end{aligned}
$$

The forecast $y_{T}(\ell)$ is computed substituting past expectations for known values and future expectations by forecast values, that is,

$\mathrm{E}\left[y_{\mathrm{T}+j} \mid \mathrm{Y}_{\mathrm{T}}\right]= \begin{cases}y_{\mathrm{T}+j} & j \leq 0 \\ y_{\mathrm{T}}(j) & j>0\end{cases}$ 
The in-sample (short term) forecast covered our initial series, that is, from January 2003 to October 2016 and output of simple exponential smoothing from $\mathrm{R}$ software tells us that the estimated value of alpha parameter is about 0.9999 . This is very close to one, implying that mush weight is placed on the most recent observation when making forecasts of future values. The results tell us that forecast for crude oil prices is based on both less recent and most recent observation with the latter having a greater impact in predicting future crude oil prices. Furthermore, we obtained the out-of-sample (long term) forecast values in predicting the crude oil price for 26 months (November 2016 to December 2018). The predicted values are given below:

Table 6. Holt-winters forecast of crude oil prices

\begin{tabular}{|c|c|c|c|}
\hline \multirow[t]{2}{*}{ Month } & \multirow{2}{*}{$\begin{array}{c}\text { Forecast } \\
\text { Value }\end{array}$} & \multicolumn{2}{|c|}{ 95\% Confidence Interval } \\
\hline & & Lower & Upper \\
\hline $2016 \mathrm{Nov}$ & 50.52 & 38.68 & 62.37 \\
\hline $2016 \mathrm{Dec}$ & 51.78 & 32.00 & 71.56 \\
\hline 2017 Jan & 53.47 & 45.04 & 61.91 \\
\hline $2017 \mathrm{Feb}$ & 54.87 & 41.55 & 65.41 \\
\hline $2017 \mathrm{Mar}$ & 55.05 & 38.87 & 68.09 \\
\hline $2017 \mathrm{Apr}$ & 56.66 & 36.61 & 70.35 \\
\hline 2017 May & 56.76 & 34.62 & 72.34 \\
\hline 2017 Jun & 56.48 & 32.82 & 74.41 \\
\hline $2017 \mathrm{Jul}$ & 57.13 & 31.16 & 75.79 \\
\hline 2017 Aug & 58.19 & 29.62 & 77.34 \\
\hline 2017 Sep & 58.14 & 28.18 & 78.78 \\
\hline 2017 Oct & 59.39 & 26.81 & 80.15 \\
\hline $2017 \mathrm{Nov}$ & 56.44 & 25.51 & 81.45 \\
\hline $2017 \mathrm{Dec}$ & 63.07 & 24.26 & 82.70 \\
\hline 2018 Jan & 61.78 & 23.07 & 83.89 \\
\hline $2018 \mathrm{Feb}$ & 59.78 & 21.92 & 85.04 \\
\hline $2018 \mathrm{Mar}$ & 57.64 & 20.81 & 86.15 \\
\hline $2018 \mathrm{Apr}$ & 57.55 & 19.74 & 87.22 \\
\hline 2018 May & 57.98 & 18.70 & 88.25 \\
\hline 2018 Jun & 59.31 & 17.69 & 89.26 \\
\hline $2018 \mathrm{Jul}$ & 59.53 & 16.72 & 90.24 \\
\hline $2018 \mathrm{Aug}$ & 59.64 & 15.76 & 91.20 \\
\hline $2018 \mathrm{Sep}$ & 58.79 & 14.83 & 92.13 \\
\hline 2018 Oct & 58.10 & 13.92 & 93.04 \\
\hline 2018 Nov & 60.27 & 13.03 & 93.93 \\
\hline $2018 \mathrm{Dec}$ & 61.45 & 12.16 & 94.79 \\
\hline
\end{tabular}

The result shows $95 \%$ prediction interval for the forecast. For instance, the forecasted crude oil price for January 2017 is about $\$ 53.47 \mathrm{pb}$, with prediction interval of $(\$ 45.04, \$ 61.91)$, while the first quarter 2018 crude oil price experienced values ranging from $\$ 60$ to $\$ 58$ per barrel approximately. The forecast results empirically support the forecast results of Poon and Grander [19] and Gabralla and Abraham [10]. The 95\% plot of the prediction made by the forecast is given as the shaded portion in the figure below:

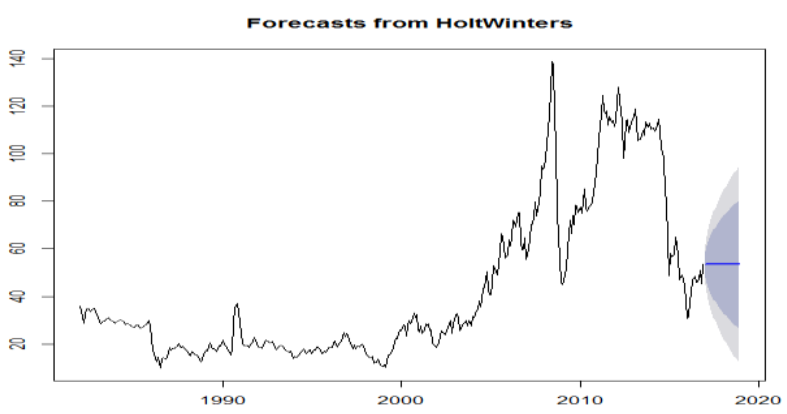

Figure 5. Forecast of crude oil prices using holt winters

\section{CONCLUSION}

The empirical analysis indicated that the $\operatorname{ARIMA}(1,1,0)$ and $\operatorname{GARCH}(1,1)$ models are best for forecasting the crude oil price data series within the sampled period as indicated from the diagnostic criteria. The paper also established that the GARCH $(1,1)$ model captures volatility clustering and leptokurtosis present in high frequency crude oil price data. From the discussions, we observe that the simple structure of the model imposes important limitations on GARCH models. Thus: (i) GARCH models, however, assume that only the magnitude and not the positivity or negativity of unanticipated excess returns determines conditional variance $\sigma_{t}^{2}$. If the distribution of $z_{t}$ is symmetric, the change in variance tomorrow is conditionally uncorrelated with excess returns of today. (ii) The GARCH models are not able to explain the observed covariance between $\varepsilon_{t}^{2}$ and $\varepsilon_{t-j}$. This is possible only if the conditional variance is expressed as an asymmetric function of $\varepsilon_{t-j}$. The kurtosis of the series is less than 3 which reveals that the series has a normal distribution and it can be seen that the series could probably be identified using an additive mode since the random fluctuation in the data are rough constant over time. From the crude oil prices series plot, it is evident that the series is a non-seasonal time series because it consists of both a trend component and an irregular component. However, the data was smoothed to have a clearer picture of the trend component. The independent and impartial crude oil price information evident in this paper will aid to promote sound policymaking, efficient markets and understanding of crude oil price, and its interaction with the economy and the environment.

The paper also suggests that the government (federal) should do everything within her reach to check the ugly trends that go on in the oil industry. These include: the activities of the restive Niger-Delta Youths that has caused a lot of harm in terms of oil production and export in Nigeria - thereby affecting tanker shipping to the record loss of up to 200,000 barrels of crude oil a day, Imam [11]. Because of this inferno, Nigeria has not been able to meet up with her daily organization of petroleum exporting countries (OPEC) quota of some 2.5 million barrels of oil per day. This means a whooping cut in Nigeria's daily income and thereby the gross domestic income (GDI); Sabotage from the Government Juggernauts whereby some high-ranking government officials engage in crude oil business without proper accountability. This in the long-run implies much more revenue to individual government officials and impoverishment of the entire country. No wonder so many Nigerians are richer than some countries in Africa.

\section{REFERENCES}

[1] Akaike H. (1974). A new look at the statistical model identification. IEEE Transactions on Automatic Control AC-19: 716-723.

[2] Bartlett MS. (1946). On the theoretical specification of sampling properties of autocorrelated time series. Journal of the Royal Statistical Society B 8: 27-41. https://doi.org/10.2307/2983611

[3] Bollerslev T. (1986). Generalized autoregressive conditional heteroskedasticity. Journal of Econometric 31: 307-327. https://doi.org/10.1016/03044076(86)90063-1 
[4] Box GEP, Jenkins GM. (1976). Time series analysis: Forecasting and control. revised edition, San Francisco: Holden Day. https://doi.org/10.1111/j.14679892.2009.00643.x

[5] Central Bank of Nigeria (CBN). (2009). Annual Reports and statement of Accounts for the year ended 31st December.

[6] Contreras J, Espinola R, Nogales FJ, Conejo AJ. (2003). ARIMA models to predict next day electricity prices. IFEE Transactions on Power System 18(3): 1014-1020. https://doi.org/10.1109/MPER.2002.4312577

[7] Dickey DA, Fuller WA. (1979). Distribution of the estimators for autoregressive time series with a unit root. Journal of the American Statistical Association 74: 42731. https://doi.org/10.1109/MPER.2002.4312577

[8] Engle, Robert F. (1982). Autoregressive conditional heteroscedasticity with estimates of variance of United Kingdom Inflation. Econometric 50: 987-1008. https://doi.org/10.2307/1912773

[9] Energy Information Administration (EIA) (2004). U.S. Primary Energy Consumption by Source and Sector.

[10] Gabralla LA, Abraham A. (2013). Computational modeling of crude oil price forecasting: A review of two decade of research. International Journal of Computer Information System and Industrial Management Applications 5: 729-740.

[11] Imam RO. (2017). ARIMA model for forecasting crude oil prices in Nigeria. An M.Sc. Project, Department of Mathematics, University of Lagos, Nigeria.

[12] Kwiatkowski D, Phillips CBP, Schmidt P, Shin Y. (1992). Testing the null hypothesis of stationarity against the alternative of a unit root. Journal of Econometrics 54: 159-178.
[13] Ljung GM, Box GEP. (1978). On a measure of lack of fit in time series models. Biometrika 65: 297-303. https://doi.org/10.2307/2335207

[14] Mandelbrot B. (1963). The variation of certain speculative prices. Journal of Business 36: 394-419. https://doi.org/10.1007/978-1-4757-2763-0_14

[15] Onyeka-Ubaka JN. (2013). A modifield BL-GARCH for distributions with heavy tails. A Ph.D. Thesis, Department of Mathematics, University of Lagos, Nigeria.

[16] Onyeka-Ubaka JN, Abass O. (2013). Central Bank of Nigeria $(\mathrm{CBN})$ intervention and the future of stocks in the banking sector. American Journal of Mathematics and Statistics 3(6): 407-416.

[17] Onyeka-Ubaka JN, Abass O, Okafor RO. (2014). Conditional variance parameters in symmetric models. International Journal of Probability and Statistics 3(1): 17. https://doi.org/10.5923/j.ijps.20140301.01

[18] Onyeka-Ubaka JN, Abass O, Okafor RO. (2016). A generalized t-distribution based filter for stochastic volatility models. AMSE JournalS-2016-Series: Advances D 21(1): 19-37.

[19] Poon S, Grander C. (2005). Practical issues in forecasting volatility. Financial Analysis Journal 61(1): 45-56. https://doi.org/10.2469/faj.v61.n1.2683

[20] Schwert GW. (1989). Why does stock market volatility change over time? Journal of Finance 44: 1115-1153. https://doi.org/10.2307/2328636

[21] Zhu F. (2011). A negative binomial integer-valued GARCH model. Journal of Time Series Analysis 32: 5467. https://doi.org/10.1111/j.1467-9892.2010.00684.x 